Journal of Patient-Centered

Volume 2

Issue 4 -- Integrative Medicine

Article 10

$11-20-2015$

\title{
Assessing the Effectiveness of Implementation of Unified Workflow in Improvement of Medication Reconciliation for Aurora St. Luke's Family Medicine Residency Outpatients
}

Katherine Meyers Jessica Konarske Jessica J.F. Kram

Dennis J. Baumgardner

Follow this and additional works at: https://aah.org/jpcrr

Part of the Family Medicine Commons, and the Pharmaceutical Preparations Commons

\section{Recommended Citation}

Meyers K, Konarske J, Kram JJ, Baumgardner DJ. Assessing the effectiveness of implementation of unified workflow in improvement of medication reconciliation for Aurora St. Luke's Family Medicine Residency outpatients. J Patient Cent Res Rev. 2015;2:203. doi: 10.17294/2330-0698.1220

Published quarterly by Midwest-based health system Advocate Aurora Health and indexed in PubMed Central, the Journal of Patient-Centered Research and Reviews (JPCRR) is an open access, peer-reviewed medical journal focused on disseminating scholarly works devoted to improving patient-centered care practices, health outcomes, and the patient experience. 
room placement was $127.38 \mathrm{~min}$. The average delay time from scheduled surgery start was $24.26 \mathrm{~min}$. Logistic regression identified hospital facility $(\mathrm{P}<0.0001)$, surgical specialty $(\mathrm{P}<0.0001)$, patient age $(\mathrm{P}=0.0004)$ and late patient arrival $(\mathrm{P}=0.0005)$ as significant predictors of delay. Operating room delays were responsible for $\$ 444,074$ in lost revenue.

Conclusion: In our study, $88 \%$ of first start cases were delayed, the majority of which were caused by the surgeon. However, hospital facility, surgical subspecialty, patient age and arrival time also significantly affected delays. Correction of operating room delays can significantly reduce hospital costs.

\section{THIRD PLACE ORAL PRESENTATION}

Assessing the Effectiveness of Implementation of Unified Workflow in Improvement of Medication Reconciliation for Aurora St. Luke's Family Medicine Residency Outpatients

Katherine Meyers, Jessica Konarske, Jessica J.F. Kram, Dennis J. Baumgardner

Department of Family Medicine, Aurora UW Medical Group, Aurora Health Care; Center for Urban Population Health

Background: Medication errors are the most common errors occurring in hospitals. Preventable adverse drug events are linked with 1 in 5 injuries or deaths; $23 \%$ of medication errors in primary care occur due to inaccuracies in the medication list. Quality improvement projects designed to improve accuracy of outpatient medication reconciliations may decrease the number of medication errors and increase patient safety by preventing adverse drug events.

Purpose: To determine whether a unified workflow for medication reconciliation improves the accuracy of ambulatory, electronic medical record (EMR)-based patient medication records.

Methods: Retrospective study of random sample of patients from Aurora Family Medicine Residency Clinics before (prior to March 31, 2014) and after (December 10, 2014) improvements to the medication reconciliation process $(n=80$ and $n=77$, respectively). Aurora pharmacy medication lists were obtained and compared to that of the EMR. To preserve patient and caregiver confidentiality, charts were assigned arbitrary identifiers. Two-sample t-tests were used to compare pre- and post-medication reconciliation. An additional patient chart audit on pre- $(n=51)$ and post- $(n=45)$ workflow implementation to assess utilization of workflow was conducted; Fisher's exact tests were used to gauge changes $(\mathrm{P}<0.05)$.

Results: When comparing pre- and post-medication reconciliation implementation, there was a significant decrease in the number of EMR medications not on the pharmacy list (mean 0.475 vs. $0.208 ; \mathrm{P}=0.022$ ). Number of providers reviewing the EMR medication record improved significantly by $30.4 \%(\mathrm{P}=0.045)$. A downward trend in the number of unintentional medication duplicates also was observed by a $13.3 \%$ decrease $(\mathrm{P}=0.07)$.

Conclusion: Implementation of systematic workflow and care team education led to overall improvement in accuracy of EMR medication reconciliation. This quality improvement project led to identification of multiple barriers to accuracy. Future areas of focus would include continued education around current workflow and additional attention to medication compliance via out-of-date prescriptions.

\section{FIRST PLACE POSTER (tie)}

Using an Automated Model to Identify Older Patients at Risk for 30-Day Hospital Readmission and 30-Day Mortality

Ariba Khan, Mary L. Hook, Maharaj Singh, Marsha Vollbrecht, Aaron Malsch, Michael L. Malone

Department of Geriatrics, Aurora UW Medical Group; Knowledge-Based Nursing Department, Aurora Health Care; Aurora Research Institute, Aurora Health Care; Senior Services, Aurora Health Care

Background: A real-time electronic health record (EHR) predictive model that identifies older patients at risk for readmission and mortality may assist the health care team in improved patient care.

Purpose: This study was performed to generate an automated 30-day readmission and 30-day mortality risk model using data from the EHR in hospitalized older adults.

Methods: This was a retrospective cohort study. Included were patients age 65 years and older admitted to the hospital from July 2012 to December 2013. An automated predictive model was derived from variables collected from the EHR including socioeconomic factors, medical diagnoses and health care utilization. The study sample was randomly divided into derivation $(70 \%)$ and validation $(30 \%)$ cohorts. Multiple logistic regression analysis was performed to derive a prediction model. A scoring system was developed for estimating risk of 30-day readmission.

Results: The study included 11,223 patients in one hospital, of which $46 \%$ were male, $20 \%$ were age $>85$ years, $6.2 \%$ were black, $60 \%$ required emergency admission, $2.8 \%$ required an ICU stay and $62.7 \%$ were discharged home. Overall 30 -day readmission and mortality rates were $13.7 \%$ and $1.5 \%$. The risk model predicted 30-day readmission, with c-statistics of 0.62 (95\% confidence interval [CI]: $0.61-0.64)$ and 0.62 (95\% CI: $0.60-0.65)$ in the derivation and validation cohorts, respectively. A readmit risk score was developed that ranged from 0 to 20 . The readmission rate increased as the score increased: score $0-4$, readmission rate $=8.38 \%$; score $5-9$, readmission rate $=13 \%$; and score $>10$, readmission rate $20 \%$ $(\mathrm{P}<0.0001)$ in the derivation cohort. Results were similar for validation cohort. The risk model predicted 30-day all-cause mortality with c-statistics of 0.81 (95\% CI: $0.77-0.86)$ and 0.73 (95\% CI: $0.66-0.81)$ in the derivation and validation cohorts. The variables associated with mortality included discharge to nursing home, urgent admission status, social 